\title{
DERIVAÇÃO VENTRICULOPERITONEAL COM VÁLVULA NO TRATAMENTO DA HIDROCEFALIA INFANTIL
}

\author{
JOSÉ JORGE FACURE *
}

Desde fins do século passado foram descritas numerosas técnicas cirúrgicas para o tratamento da hidrocefalia. Nos últimos anos foram empregadas, com certa eficácia, as técnicas de derivação do líquido cefalorraqueano (LCR), para fora do estôjo craniorraqueano; dentre estas, a derivação ventriculoatrial (DVA) foi a mais usada. Calcula-se que, de 1957, ano em que foram divulgadas as válvulas de Holter e de Pudenz, até 1964, cêrca de 10.000 derivações ventriculovenosas tinham sido feitas. Algumas complicaçōes graves decorrentes do uso da DVA foram sendo pouco a pouco registradas: trombose da veia cava e átrio direito, microembolismo, fibrose pulmonar e cor pulmonale crônico, bacteremia, deslocamento do cateter distal para as cavidades cardíacas e perfuração do miocárdio.

Em vista disso alguns autores procuraram aperfeiçoar outras técnicas cirúrgicas, voltando suas vistas para a derivação ventriculoperitoneal (DVP), intervenção que era encarada com cepticismo por grande número de neurocirurgiōes pois, com as técnicas iniciais quase sempre era observado, algum tempo após a derivação, o bloqueio do cateter peritoneal pelo epiploon. Procurando dificultar a oclusāo do cateter alguns autores introduziram uma válvula unidirecional no sistema de drenagem. Uma série de 95 crianças hidrocefálicas foram submetidas à DVP com válvula, em um período de aproximadamente 4 anos. Julgamos oportuno analisar os resultados obtidos e comparar esta técnica com a DVA.

É objetivo deste trabalho mostrar que o tratamento da hidrocefalia infantil, mediante derivação ventriculoperitoneal com interposição de válvula, fornece bons resultados.

\section{CASUISTICA E MÉTODOS}

Nossa casuistica (Tabela 1) compreende 95 crianças hidrocefálicas submetidas à derivação ventriculoperitoneal com o uso de válvula. Foi utilizada a válvula de Spitz-Holter em 88 casos, a válvula de Hakim em 6 (casos 51, 55, 56, 66, 73 e 92) e a válvula de Pudenz-Heyer apenas no caso 71 . Os pacientes foram operados na

Tese apresentada à Faculdade de Ciências Médicas da Universidade Estadual de Campinas para obtencāo do grau de Doutor: * Médico-assistente de Clinica Neurológica (Prof. Oswaldo Freitas Julião).

Nota do autor - Ao Prof. Gilberto Machado de Almeida os nossos agradecimentos pela orientação e pelo apôio ao nosso trabalho. 
Clínica Neurológica do Hospital das Clinicas da Universidade de São Paulo (50 casos) e no Serviço de Neurocirurgia do Hospital 9 de Julho (45 casos), no periodo de dezembro de 1965 a novembro de 1969.

Das 95 crianças, 13 foram operadas por nós (casos 37, 46, 49, 60, 62, 64, 65, 69, $70,72,75,77$ e 78). Tivemos participação como primeiro auxiliar nas cirurgias de 19 pacientes (casos 19, 28, 30, 31, 38, 40, 41, 51, 54, 55, 56, 58, 63, 66, 67, 68, 71, 73 e 74). Incluindo as revisões, participamos de 50 intervenções. No periodo de julho de 1967 a março de 1969 tomamos parte no contrôle pós-operatório imediato dos outros casos. Acompanhamos também o seguimento destas crianças até 1970.

Separamos os 95 casos em duas amostras: a primeira inclui 79 casos que tiveram na derivação ventriculoperitoneal a primeira tentativa cirúrgica para o tratamento da hidrocefalia; a segunda é representada por 16 crianças submetidas anteriormente à derivação ventriculoatrial (casos $15,16,19,25,26,27,29,45,50,54$, $60,62,73,74,79$ e 83 ).

Para o total dos casos a idade variou entre 15 dias e 96 meses (mediana de 5,85 meses); na primeira amostra variou entre 15 dias e 96 meses (mediana de 4,89 meses) e, na segunda amostra, entre 6 e 95 meses (mediana de 58,59 meses).

L'studo pré-operatório da primeira amostra (79 casos) - O exame clínico-neurológico, com estudo da fontanela bregmática e medições repetidas dos perímetros cranianos, é, em geral, suficiente para o diagnóstico da hidrocefalia descompensada. Exames complementares foram realizados para excluir a possibilidade de que a macrocefalia pudesse ser relacionada com tumor, malformação vascular, meningite, megalencefalia ou hidranencefalia. Não foram efetuados, em todos os casos, os exames subsidiários para um estudo completo, por duas razōes principais: a) muitos déstes exames não são inócuos, podendo determinar graves complicações; b) não há, na prática, necessidade de diagnóstico preciso do local do bloqueio ao trânsito liquórico, uma vez que a DVP pode ser empregada qualquer que seja o nivel da oclusão. Para evitar os riscos impostos por alguns exames complementares foram realizados exames simples e inócuos (radiografia simples do crânio, exame do LCR, eletrencefalograma). Estudos neurorradiológicos foram necessários em alguns casos.

O exame do líquido cefalorraqueano (LCR) foi o que trouxe maior contribuição à avaliação pré-operatória. Procuramos realizar punções dos dois ventrículos laterais, geralmente associada à punção suboccipital ou lombar. Com a puncão ventricular nāo só colhemos material para exame, como avaliamos a espessura do pálio cerebral, o tamanho dos ventrículos e a existência de coleções extracerebrais. O exame do LCR, com punçāo combinada foi realizado em 57 pacientes. Em 4 crianças foi realizada apenas punção ventricular (casos 2, 35, 38 e 93) e, em 12, o LCR foi colhido por puncão suboccipital ou lombar (casos 6, 17, 23, 28, 31, 44, 46, 63, 64, 66, 67 e 75). Encontramos nos casos 34, 58 e 80 grande diferença na dosagem das proteinas entre o LCR colhido nos ventrículos e o colhido por via cisternal ou lombar. Este fato sugeriu a existência de bloqueio do sistema ventricular, o que foi confirmado no caso 34 pela iodoventriculografia e, no caso 58, pela pneumoventriculografia. A vigência de meningite foi constatada nos casos $2,28,95$ e 48, sendo que neste último havia também ventriculite. No caso 20 a punçāo combinada mostrou aumento de proteinas nas três amostras e. no caso 12, - LCR mostrou-se hemorrágico, sendo, em ambos, indicado estudo neurorradiológico. Nos casos 64 e 84, com o diagnóstico clínico de toxoplasmose, o exame revelou hipercitose linfomononuclear.

O estudo do LCR não foi realizado apenas em 6 pacientes dêste grupo, 5 dêles (casos 7, 40, 68, 89 e 92) apresentando meningocele; nestes casos êste exame é feito apenas quando há necessidade de afastar intercorrencia infecciosa ou hemorrágica. No caso 8 o exame foi contraindicado pela existência de hipertensão intracraniana severa.

A radiografia simples do crânio não é elemento seguro para o diagnóstico precoce ou para verificr a existência de descompensação. Assume maior importância 


\begin{tabular}{|c|c|c|c|c|c|}
\hline Caso & Nome & Idade & Sexo & Data & Reg. \\
\hline 1 & NM & 1 & F & $28-12-65$ & 788.756 \\
\hline 2 & VAS & 11 & $\mathbf{M}$ & $18-1-66$ & 780.174 \\
\hline 3 & SMO & 5 & $\mathbf{F}$ & $15-2-66$ & 795.452 \\
\hline 4 & PSP & 8 & $\mathbf{M}$ & $15-2-66$ & 787.534 \\
\hline 5 & NE & 4 & $\mathbf{F}$ & $8-3-66$ & 796.913 \\
\hline 6 & MAS & 12 & $\mathbf{F}$ & $15-3-66$ & 784.283 \\
\hline 7 & $\mathrm{JCS}$ & 2 & $\mathbf{F}$ & $7-5-66$ & \\
\hline 8 & JL & 59 & $\mathbf{M}$ & $3-6-66$ & \\
\hline 9 & JMLR & 7 & F & $7-6-66$ & 802.913 \\
\hline 10 & MK & 2 & $\mathbf{M}$ & $11-6-66$ & \\
\hline 11 & vB & 12 & $\mathbf{F}$ & $14-6-66$ & 804.563 \\
\hline 12 & PRT & 4 & $\mathbf{M}$ & $10-7-66$ & \\
\hline 13 & MAM & 7 & $\mathbf{M}$ & $13-7-66$ & 806.111 \\
\hline 14 & LFP & 11 & $\mathbf{M}$ & $2-8-66$ & 792.110 \\
\hline 15 & MV & 6 & $\mathbf{F}$ & $11-8-66$ & \\
\hline 16 & EM & 42 & $\mathrm{~F}$ & 1-9-66 & \\
\hline 17 & EZR & 19 & $\mathbf{M}$ & $11-9-66$ & \\
\hline 18 & MAHA & 5 & $F$ & $20-9-66$ & 808.978 \\
\hline 19 & MM & 83 & $\mathrm{M}$ & $25-10-66$ & 581.817 \\
\hline 20 & MLSC & 6 & $F$ & $1-11-66$ & 814.677 \\
\hline 21 & NPM & 3 & $\mathbf{M}$ & $4-11-66$ & \\
\hline 22 & $\mathrm{JCS}$ & 5 & $\mathbf{M}$ & $23-11-66$ & 816.292 \\
\hline 23 & PENA & 41 & $\mathbf{M}$ & $19-12-66$ & \\
\hline 24 & SV & 5 & $\mathrm{~F}$ & $27-12-66$ & 820.280 \\
\hline 25 & MEF & 66 & $\mathbf{F}$ & $10-1-67$ & 643.256 \\
\hline 26 & $\mathrm{CBA}$ & 33 & $\mathbf{M}$ & $26-1-67$ & 750.206 \\
\hline 27 & CMA & 23 & $\mathbf{M}$ & $14-2-67$ & 762.699 \\
\hline 28 & $\mathrm{RMB}$ & 2 & $\mathrm{~F}$ & $15-2-67$ & \\
\hline 29 & LCO & 24 & $\mathbf{M}$ & $7-3-67$ & 762.593 \\
\hline 30 & WK & 3 & $\mathbf{M}$ & $15-3-67$ & \\
\hline 31 & LFS & 27 & F & $22-3-67$ & \\
\hline 32 & sSS & 5 & $\mathbf{M}$ & $22-3-67$ & 826.777 \\
\hline 33 & $\mathrm{JCC}$ & 5 & $\mathbf{M}$ & $13-4-67$ & 819.971 \\
\hline 34 & RFP & 21 & $\mathbf{M}$ & $27-4-67$ & \\
\hline 35 & os & 36 & $\mathbf{M}$ & $16-5-67$ & 808.547 \\
\hline 36 & FVB & 9 & $\mathbf{M}$ & $16-5-67$ & 839.523 \\
\hline 37 & UP & 2 & $\mathbf{F}$ & $22-5-67$ & \\
\hline 38 & LBG & $1 / 2$ & $F$ & $29-5-67$ & \\
\hline 39 & AFCG & 10 & $\mathbf{M}$ & $20-6-67$ & 836.703 \\
\hline 40 & MPVF & 2 & $\mathbf{F}$ & $29-6-67$ & \\
\hline 41 & PJB & 2 & $\mathbf{M}$ & $8-7-67$ & \\
\hline 42 & JAAS & 8 & $\mathbf{M}$ & $18-7-67$ & 837.113 \\
\hline 43 & JCG & 1 & $\mathbf{M}$ & $8-8-67$ & 649.395 \\
\hline 44 & MFS & 37 & $\mathbf{F}$ & $29-8-67$ & 841.781 \\
\hline 45 & MAD & 58 & $F$ & 6-9-67 & 684.929 \\
\hline 46 & $\mathrm{PC}$ & 8 & $F$ & $26-9-67$ & \\
\hline 47 & MES & 5 & $\mathbf{M}$ & $11-10-67$ & 849.658 \\
\hline 48 & EAO & 7 & $\mathbf{F}$ & $23-10-67$ & 842.801 \\
\hline 49 & PAO & 7 & $F$ & $6-11-67$ & \\
\hline
\end{tabular}




\begin{tabular}{|c|c|c|c|c|c|}
\hline Caso & Nome & Idade & Sexo & Data & Reg. \\
\hline 50 & MMC & 59 & $\mathbf{F}$ & $21-11-67$ & 693.554 \\
\hline 51 & ENB & 1 & $\mathbf{M}$ & $8-12-67$ & \\
\hline 52 & MLL & 2 & $\mathbf{F}$ & $16-1-68$ & 856.488 \\
\hline 53 & AIM & 4 & $\mathbf{F}$ & $6-2-68$ & 861.080 \\
\hline 54 & VLS & 19 & $\mathbf{M}$ & $20-3-68$ & \\
\hline 55 & JB & 4 & $\mathbf{M}$ & $28-3-68$ & \\
\hline 56 & ASSP & 6 & $\mathbf{F}$ & $28-3-68$ & \\
\hline 57 & CAP & 8 & $\mathbf{M}$ & $17-4-68$ & 861.045 \\
\hline 58 & $\mathrm{CC}$ & 13 & $\mathbf{F}$ & $28-5-68$ & \\
\hline 59 & SLCC & 3 & $\mathbf{M}$ & $23-7-68$ & 857.358 \\
\hline 60 & MMM & 64 & $\mathbf{F}$ & $14-8-68$ & 684.277 \\
\hline 61 & EF & 5 & $\mathbf{M}$ & $11-9-68$ & 876.929 \\
\hline 62 & RNVP & 57 & $\mathbf{F}$ & $19-9-68$ & 725.978 \\
\hline .63 & JP & 8 & $\mathbf{F}$ & $3-10-68$ & \\
\hline 64 & FES & 2 & $\mathbf{M}$ & $16-10-68$ & \\
\hline 65 & SGP & 7 & $\mathbf{F}$ & $18-10-68$ & \\
\hline 66 & HPJ & 96 & $\mathbf{M}$ & $12-11-68$ & \\
\hline 67 & AMF & 16 & $\mathbf{M}$ & $19-11-68$ & \\
\hline 68 & EBO & 6 & $\mathbf{M}$ & $20-11-68$ & \\
\hline 69 & ALP & 6 & $\mathbf{M}$ & $27-11-68$ & 882.043 \\
\hline 70 & MNFR & 5 & $\mathbf{F}$ & $28-11-68$ & \\
\hline 71 & JMB & 4 & $\mathbf{M}$ & $10-12-68$ & \\
\hline 72 & RO & 6 & $\mathbf{F}$ & $14-12-68$ & 883.071 \\
\hline 73 & MPC & 83 & $\mathbf{F}$ & $5-1-69$ & \\
\hline 74 & $\mathrm{SC}$ & 86 & $\mathbf{F}$ & $29-1-69$ & \\
\hline 75 & EEJ & 3 & $\mathbf{M}$ & 4-3-69 & \\
\hline 76 & AAM & 16 & $\mathbf{F}$ & 5-3-69 & 879.456 \\
\hline 77 & MSM & 3 & $\mathbf{F}$ & & \\
\hline 78 & EFM & 1 & $\mathbf{M}$ & $25-3-69$ & \\
\hline 79 & ECS & 95 & $\mathbf{F}$ & $7-4-69$ & \\
\hline 80 & MEF & 2 & $\mathbf{M}$ & $15-4-69$ & 894.790 \\
\hline 81 & MA & 3 & $\mathbf{F}$ & $16-4-69$ & \\
\hline 82 & EM & 3 & $\mathbf{M}$ & 3-6-69 & \\
\hline 83 & $\mathrm{CSC}$ & 63 & $\mathbf{M}$ & $8-6-69$ & \\
\hline 84 & ECA & 3 & $\mathbf{M}$ & $15-7-69$ & \\
\hline 85 & CJS & 4 & $\mathbf{M}$ & $21-7-69$ & \\
\hline 86 & MVL & 1 & $\mathbf{F}$ & $22-7-69$ & 906.792 \\
\hline 87 & PSMD & 4 & $\mathbf{M}$ & $30-9-69$ & 909.658 \\
\hline 88 & $\mathrm{CCS}$ & 10 & $\mathbf{M}$ & $30-9-69$ & 908.060 \\
\hline 89 & EFB & 3 & $\mathbf{M}$ & $15-10-69$ & 907.532 \\
\hline 90 & $\mathbf{F Q}$ & 2 & $\mathbf{F}$ & $29-10-69$ & 908.059 \\
\hline 91 & GSC & 3 & $\mathbf{M}$ & 6-11-69 & 914.419 \\
\hline 92 & OCA & 3 & $\mathbf{M}$ & $11-11-69$ & \\
\hline 93 & FAC & 8 & $\mathbf{M}$ & $13-11-69$ & \\
\hline 94 & MMA & 2 & $\mathbf{M}$ & 14-11-69 & 909.624 \\
\hline 95 & MKZ & 2 & $\mathbf{M}$ & $26-11-69$ & 912.116 \\
\hline
\end{tabular}

Tabela 1 - Dados de identificacão $e$ registro dos 95 casos. Idade em meses. Reg. = nimero de registro no Hospital das Clfnicas da FMUSP. 
no estudo de crianças maiores, podendo mostrar hipertensão intracraniana recente. O estudo radiológico simples do crânio foi feito em 54 crianças. No caso 63 , mostrou calcificaçōes sugestivas de toxoplasmose e, nos $\operatorname{casos} 8,23,34$ e 66 , sinais de hipertensão intracraniana recente.

o eletrencefalograma é elemento de valor. Nos casos em que revela assimetria, poderá fortalecer a indicacão de estudo neurorradiológico. Assume especial importância no diagnóstico diferencial com hidranencefalia. ${ }^{24}$ Foi realizado em 46 casos. Em 32 resultou normal. Evidenciou sinais de sofrimento cerebral unilateral em 7 (casos 4, 24, 32, 52, 69, 76 e 90), sinais de sofrimento cerebral difuso em três (casos 5,66 e 84 ) e presença de foco irritativo nos casos $8,11,38$ e 58 .

Os exames neurorradiológicos foram realizados apenas em 14 casos da presente série. O estudo foi indicado principalmente para as crianças com descompensação tardia ou quando o exame clínico, o eletrencefalograma e/ou as punçoes combinadas forneceram dados atipicos, exigindo estudo mais completo para excluir tumores, abscessos, malformaçōes vasculares, coleçōes subdurais e megalencefalia. Nos casos $8,34,35,44,58$ e 76 houve descompensação tardia e o exame clínico, a evolução e os exames complementares não contrastados indicaram a necessidade de estudo neurorradiológico. Nos casos 8 e 44 a descompensação foi relacionada com traumatísmo de crânio recente e, no caso 58, com meningite, nos demais, não apuramos fatôres que pudessem ser relacionados com a descompensaçāo. No caso 8 foi realizada apenas angiografia cerebral que demonstrou existência de dilatação ventricular. Nos casos 34,44 e 58, o estudo angiográfico mostrou sinais indiretos de dilatação ventricular; foi realizada iodoventriculografia nos dois primeiros que demonstrou a existência de bloqueio do tipo inflamatório ao nivel do aqueduto de Sylvius, no caso 34 , e, ao nivel da transição ventriculocisternal, no caso 44; estudo com injeção de ar no ventrículo lateral esquerdo mostrou, no caso 58 , estar o ventrículo dilatado, deformado e com septações. No caso 35 a lodoventriculografia mostrou a existência de bloqueio do tipo inflamatório ao nivel do aqueduto cerebral. Nos casos 10 e 33 a descompensação efetuou-se muito ràpidamente tendo sido realizada angiografia carotidiana para diagnóstico diferencial; o exame mostrou apenas dilatacão ventricular. A existência de sinais neurológicos focais, nos casos 24 e 36 , indicou estudo angiográfico, que apenas revelou dilatação ventricular. No caso 20 , o aumento de proteinas no LCR foi o elemento que justificou a realizaçāo da angiografia que afastou outras etiologias. O quadro clínico, no caso 67 , nos orientou para a realização de pneumencefalografia que evidenciou agenesia do corpo caloso. No caso 76, a angiografia cerebral sugeriu a existência de processo expansivo avascular, que o estudo pneumencefalográfico demonstrou corresponder a cavidade porencefálica. Nos casos 12 e 57, em virtude da etiologia traumática, foram realizadas angiografias que demonstraram apenas dilatação ventricular. No caso 12 o estudo prosseguiu mediante pneumencefalografia que revelou bloqueio nas cisternas da base e septaçōes no ventriculo lateral esquerdo.

E'studo pré-operatório da segunda amostra - Esta amostra reúne 16 pacientes hidrocefálicos que haviam sido submetidos, anteriormente, à derivação ventriculoatrial. Complicaçōes diversas impuseram revisões cirúrgicas, tendo sido realizada em todos uma derivação ventriculoperitoneal.

No estudo pré-operatório desta série faremos referéncias aos exames efetuados para a avaliação da hidrocefalia, bem como àqueles realizados para o estudo das complicacoōes decorrentes das drenagens para a corrente sangüinea.

A radiografia simples do crânio, o eletrencefalograma, o exame do líquido cefalorraqueano foram realizados em todos os pacientes desta série. O estudo radiológico simples do crânio mostrou, em todos os casos, macrocefalia com adelgaçamento das tábuas ósseas. No caso 29 evidenciou também posição anormalmente alta dos sulcos dos seios transversos. O eletrencefalograma mostrou sinais de sofrimento cerebral unilateral nos casos 19 e 60 , sendo normal nos demais. O líquido cefalorraqueano foi colhido por punção ventricular nos casos 29 e 83, por punção suboccipital nos casos 16 e 60 , sendo que, nos demais, foram realizadas puncōes 
combinadas. Apenas no caso 73 o exame mostrou-se alterado, com LCR fortemente hemorrágico. O estudo neurorradiológico foi indicado nos casos 29 e 60 . No primeiro, o tempo venoso da angiografia cerebral confirmou a posição anormalmente alta dos seios transversos, firmando o diagnóstico de sindrome de Dandywalker. No segundo, em paciente com doenca de Appert, o estudo pneumencefalográfico confirmou a existência de dilatação ventricular.

Após esta avaliação pré-operatória os pacientes foram submetidos à derivação ventriculoatrial. Em virtude de várias intercorrências, foi feit a DVP, após um período variável de três a 84 meses (mediana de 51,5 meses). Nos casos 15,16 e 19 manifestações clinicas de bacteremia determinaram a mudança da técnica cirúrgica; no caso 15 , o exame do LCR mostrou a coexisténcia de meningite; nos outros dois, o LCR colhido por punção suboccipital foi normal. O eletrocardiograma, feito nos casos 16 e 19, evidenciou sinais compatíveis com o diagnóstico de sobrecarga direita; dois meses após a DVP, êstes sinais desapareceram. Nos caso 45 e 54 houve intercorrēncia infecciosa, com meningite confirmada pelo LCR e com supuração ao longo do cateter atrial.

A radiografia simples do crânio presta grande contribuição ao estudo dos pacientes já operađos. Nos casos em que haja suspeita de que o sistema de drenagem nāo esteja funcionando, exames repetidos podem mostrar aumento dos sinais de hipertensão intracraniana. Além disto, a posiçâo dos cateteres e da própria válvula pode ser controlada pela radiografia simples. O exame foi realizado nos casos $25,26,27,29,50,60,62,73,74,79$ e 83 , com suspeita de que o sístema de drenagem não funcionava bem. Mediante êste estudo fizemos o diagnóstico de rotura do cateter distal nos casos 25 e 62, rotura do cateter ventricular nos casos 26 e 27 e rotura dos dois cateteres no caso 73. Esses achados rdiológicos foram confirmados durante o ato cirúrgico, que consistiu na transformação da DVA em DVP. No restante dos casos, a radiografia simples do crânio nâo contribuiu para esclarecer o mau funcionamento do sistema. Porém, em virtude do quadro clínico de descompensação, êstes pacientes foram reoperados. Nos casos 29, 60 e 74, encontrou-se oclusāo do cateter atrlal; no caso 50, rotura parcial do cateter distal e, nos casos 79 e 83 , foi diagnosticada oclusão do cateter ventricular.

Etiologia - Os dados clínicos, laboratoriais e necroscópicos, permitiram determinar a causa da hidrocefalia apenas em parte dos 95 casos estudados.

Em 7 crianças (casos $2,9.11,28,35,50$ e 58) a hidrocefalia seguiu-se à meningite purulenta. No caso 2 a necrópsia não evidenciou bloqueio. No caso 35 a iodoventriculografia revelou bloqueio do tipo inflamatório ao nivel do aqueduto cerebral. No caso 58 o exame do LCR mostrou meningite e ventriculite, sugerindo ainda hidrocefalia bloqueada, confirmada pela pneumoventriculografia. Nos demais, a pur:cão combinada sugeriu tratar-se de hidrocefalia do tipo comun:eante.

Em três pacientes, casos 63,64 e 84, a hidrocefalia foi determinada por toxoplasmose. No caso 63, a ladiografia simples do crânio mostrou calcificaçōes sugestivas de toxoplasmose. Nos casos 64 e 84 havia microftalmia. Em todos os três, a reação de Sabin-Feldman apresentou títulos elevados (1:32.000 ou mais alto).

Em três casos a hidrocefalia foi determinada por hemorragia subaracnóidea consequiente a traumatismo ocorrido no parto (casos 57 e 73) ou nos primeiros meses de vida (caso 12). A pneumencefalografia do caso 12 evidenciou bloqueio das cisternas da base e septacões no ventriculo lateral esquerdo.

Malformaçōes foram diagnosticadas em 18 casos: 12 com meningomielocele lombossacra (casos $7,15,16,68,79,81,87,89,90,91,92$ e 95), dois com meningencefalocele occipital (casos 29 e 86), um com meningomielocele dorsal (caso 40), doenca de Appert (caso 60), agenesia do corpo caloso (caso 67) e porencefalia (caso 76). Entre os pacientes com meningencefalocele occipital, um apresentava sindrome de Dandy-Walker (caso 29) e, outro, de Arnold-Chiari (caso 86).

Nos 64 casos restantes não foi possivel estabeiecer a etiologia da hidrocefalia. Nos $\operatorname{csos} 34$ e 44, a iodoventriculografia mostrou bloqueio do tipo inflamatório ao 
nivel do aqueduto cerebral, no primeiro, e, ao nivel da transição ventriculocisternal, no segundo.

Indicação cirürgica - Todos os 95 pacientes da presente série foram levados à cirurgia na vigência de hidrocefalia evolutiva ou descompensada. $O$ exame clinico, com estudo da fontanela bregmática e medidas dos perímetros cranianos, confirmou a descompensação. Algumas crianças com crescimento lento do crânio foram observadas por algum tempo, antes da indicação cirúrgica, devido à possibilidade de ocorrer compensação espontânea.

Em 7 casos foram necessárias operacões de urgências. Dois dos pacientes (casos 19 e 62) tinham sido submetidos à derivaçōes ventriculoatriais que foram removidas: no pósıoperatório imediato surgiu quadro de hipertensāo intracraniana aguda, exigindo derivação ventriculoperitoneal de urgência. Nos demais, a severidade do quadro clínico determinou a intervençāo de urgência.

I'écnica cirúrgica - A técnica operatória para a derivação ventriculoperitoneal não apresenta diferenças com a proposta por Spitz : para a instalação do sistema ventriculoatrial, no que diz respeito à adaptaçāo da válvula e do cateter ventricular. O cateter peritoneal é introduzido na cavidade mediante incisão para-mediana, dois a três cm acima do umbigo. Em 88 pacientes empregamos o sistema de Spitz-Holter; no caso 71 foi utilizado o sistema de Pudenz-Heyer e, em 6 criancas, o sistema de Hakim. 10

A técnica cirúrgica constou dos seguintes tempos: a) incisão semicircular parietal posterior, trepanação, retirada de osso na parte interior para adaptar a válvula; b) incisāo supraclavicular e colocacão do cateter peritoneal no subcutâneo, utilizando-se uma pinça de Bozeman; c) fixação da extremidade inferior da válvula ao cateter peritoneal com fio de algodão $10 ; d$ ) introdução do cateter ventriculai no ventriculo lateral, procuranjo colocar sua extremidade no côrno frontal; $e$ ) veríficação do funcionamento do sistema depois de fixar o cateter ventricular à parte superior da válvula e, esta, ao plano ósseo, com fio de algodão 10 (fluxo satísfatório e ausência de refluxo); $f$ ) incisão para-mediana dois a três cm acima do umbigo; $g$ ) com o auxilio da pinça de Bozeman, condução da extremidade do cateter peritoneal até a incisão abdominal, mediante túnel feito no tecido celular subcutâneo; $h$ ) abertura do peritônio, prèviamente reparado com sutura em bôlsa, e introduçāo de cêrca de 30 a $40 \mathrm{~cm}$ do cateter de silástico na cavidade peritoneal; i) fechamento dos planos superficials.

A primeira operacão foi sempre realizada no lado direito, exceto nos casos $15,19,26,29,45$ e 62 .

As válvulas de Pudenz-Heyer e de Hakim foram instaladas de maneira semelhante. No sistema de Pudenz, o que se fixa ao osso parietal é uma cápsula siliconizada que une os dois cateteres, uma vez que a válvula localiza-se na extremidade peritoneal. A válvula de Hakim apresenta algumas vantagens, sendo de aço inoxidável. O conjunto desenhado por Hakim possui ainda um reservatório siliconizado de instalaçāo opcional, utilizado para testar ou desobstruir o sistema, colhêr LCR ou introduzir antibiótícos.

L'studo pós-operatório - Uma vez instalado o sistema de drenagem ventriculoperitoneal procuramos, mediante exame clinico e utilizacão de testes de funcionamento da válvula, surpreender a ocorrência de descompensação da hidrocefalia e diagnosticar precocemente as complicaçôes. Para êste fím, foram realizados também alguns exames complementares.

A radiografia simples do crânio foi realizada em 11 pacientes. Nos casos 23 e 31 a sequêencia do estudo radiológico mostrou aumento de disjunşão de suturas, tendo sido indicada nova cirurgia. No caso 74 a radiografia evidenciou rotura do cateter ventricular, confirmada durante a revisão. Nos casos 6 e 56, nos quais o sistema havia sido retirado, o estudo radiológico afastou a presença de hipertensão 
intracraniana atual. Nos casos 28, 29, 57, 80, 90 e 93, a radiografia realizada para verificar a posição dos elementos de drenagem, mostrou que os mesmos mantinham posiçảo adequada.

O teletrencefalograma, realizado em 14 pacientes, foi normal em 10 . Nos casos 30 e 73, mostrou sinais de sofrimento cerebral em um hemisfério. Nos casos 6 e 51 foi registrado traçado hipsarritmico. Nos casos 11, 19, 32 e 90, o estudo mostrou melhora, com traçado normal, sendo que o estudo pré-operatório havia revelado foco irritativo no caso $11 \mathrm{e}$, sofrimento cerebral unilateral, nos outros três.

O exame do LCR foi feito em 34 pacientes: confjrmou a presenca de meningite em 22, sendo normal em 12.

O estudo neurorradiológićo foi realizado apenas em três pacientes: pneumencefalografia fracionada, no caso 34 , confirmou posição normal do IV ventriculo; o estudo angiográfico, nos casos 66 e 73, confirmou a existência de hematoma subdural.

Kevisōes cirürgicas - Após a drenagem para o peritōnio, foram realizadas $\mathbf{5 . 1}$ reoperaçōes em 31 hidrocefálicos, totalizando 149 atos cirúrgicos visando à: retirada do sistema por infecção ( 21 casos); nova derivação após retirada do sistema (12); revisão do cateter ventricular (8); revisão do cateter peritoneal (5); substituicão da válvula por drenagem insuficiente (4); tratamento do hematoma subdural (2); nova derivaçāo sem retirada do sistema (1); retirada por penetracão no intestino grosso (1).

Métodos estatisticos * — Para a interpretação dos resultados e comentários de alguns dados obtidos, realizamos estudos estatístico complementar. Na caracterização da amostra usamos a mediana ao invés da média, em virtude dos dados quantitativos não apresentarem distribuição normal; a unidade de mês foi considerada igual a 30 dias. Para a análise da associação, entre atributos qualitativos, foram executados testes de homogeneidade (testes do $\mathrm{X}^{2}$ ). Nos tabelas com frequências pequenas foi aplicado o teste do $\mathrm{X}^{2}$ com correção para continuidade de Yates. Quando um dos atributos era qualitativo e o outro quantitativo, em virtude de tratar-se de dados não paramétricos, foi aplicado o teste de Wilcoxon. As médias paramétricas foram localizadas em intervalos de confiança de $95 \%$. Foi elaborada uma "Tábua de Vida" (análise das probabilidades de "sobrevivência" a uma revisão cirúrgica, óbito e seqüela neurológica grave), baseada em publicação do Departamento de Bioestatistica da Faculdade de Medicina da Universidade do Chile.

\section{R E S U L T A D O S}

O periodo maior de seguimento pós-operatrio foi de 4 anos (casos $6,10,14$ e 16 ). Nove pacientes não voltaram à consulta após a alta hospitalar (casos $8,13,15,38$, $47,49,54,77$ e 92). Nove crianças faleceram (casos $2,3,24,35,43,52,53,65$ e 86), sendo que apenas no caso 65 o óbito ocorreu mais de três meses após a cirurgia. Os dados relativos às condições e seguimento dos pacientes, computados no ano de 1970, figuram na tabela 2 .

Complicaçōes - Complicacōes infecciosas foram observadas 31 vêzes (20,8\% do total de intervençôes), em 29 doentes (30,5\% do total de casos). Meningite ocorreu em 24 pacientes, supuração ao longo do trajeto do sistema de drenagem em 10; em três dêstes casos houve fistula liquórica, com supuracão ao nivel da cicatriz craniana, evoluindo para meningite.

* O estudo estatístico foi orientado pelo Dr. Walter Pinto Júnior, médico-assistente do Departamento de Genćtica Médica, Faculdade de Ciências Médicas da Universidade Estadual de Campinas. 
Mediana de seguimento em meses

\begin{tabular}{|c|c|c|c|}
\hline Hidrocefalia compensada ..... & 54 & 3 a 48 & 24,5 \\
\hline$\ldots \ldots \ldots \ldots$ & 32 & $1 / 2$ a 36 & 4,5 \\
\hline Obitos $\ldots \ldots \ldots \ldots$ & 9 & $1 / 2$ a $51 / 2$ & 1.7 \\
\hline
\end{tabular}

Tabela 2 - Condições dos pacientes no ano de 1970

Relacionando a idade com que os pacientes foram operados e a probabilidade de ocorrer meningite no pós-operatório, utilizando o método estatístico de wilcoxon, obtivemos um resultado de $Z=1,11$ ( $Z$ crítico, ao nivel de $5 \%$ igual a 1,96 ). O que equivale a dizer que a ocorrência de meningite no pós-operatório não está associada à idade do paciente na época do ato cirúrgico.

Meningite ocorreu até o segundo mês de seguimento pós-operatório em $79,17 \%$ dos casos (nesse grupo, o período de observação até o aparecimento da meningite, corresponde à uma mediana de 0,6 meses). Nos demais casos $(20,83 \%)$ a meningite ocorreu após o segundo mês (mediana de 3,4 meses). Dois pacientes (casos 65 e 73) apresentaram meningite após revisāo círúrgica efetuada, respectivamente, dois e sete meses após a DVP; nos demais, a infecção seguiu-se à primeira drenagem para o peritônio.

Da série de pacientes que tiveram infecç̃o, 5 (casos 16, 29, 60, 62 e 73) tinham sido submetidos, anteriormente, à DVA. Nesse grupo, em duas crianças (casos 60 e 73), após retirada do sistema e cura do processo infeccioso, foram feitas novas derivacooes para o peritonio, que foram também retiradas em virtude de reinfecção.

No total de 29 doentes com infeção foram realizadas 47 reoperações $(87,03 \%$ do total). Nesse grupo, 7 criancas submetidas a novas drenagens evoluiram bem (casos 16, 51, 56, 62, 70, 78 e 82). Sete pacientes tiveram a hidrocefalia compensada após retirada do sistema e cura da infecção, nāo havendo necessidade de nova drenagem (casos 6, 18, 46, 60, 69, 73 e 80). Em 4 (casos 5, 12, 29 e 48), houve cura do processo infeccioso sem retirada do sistema de drenagem; nestes casos, embora fossem nitidos os quadros clínico e laboratorial de meningite, nāo foj possivel isolar o agente etiológico. Dois pacientes (casos 30 e 85 ), reoperados, apresentaram maus resultados. No caso 30 , logo após a realização da DVP esquerda, surgiu convulsâo no hemicorpo direito, seguida de hemiparesia; o eletrencefalograma evidenciou sofrimento cerebral no hemisfério esquerdo e uma pesquisa de coleção subdural foi negativa; houve contrôle das convulsōes e apenas discreta melhora do déficit motor, apesar do tratamento fisioterápico. No caso 85 a DVP esquerda nāo funcionou bem, por enchimento deficiente da válvula. Dos pacientes com meningite, 9 faleceram (casos 2, 3, 24, 35, 43, 52, 53, 65 e 86).

Estudamos a associação entre a ocorrência, ou não, de meningite e o resuItado sendo enquadrados, nesse grupo, apena os pacientes com tempo de seguimento superior a dois meses (tabela 3 ). O teste do $\mathrm{X}^{2}$, com correção para continuidade, mostrou que a diferença é significante mesmo ao nível de $1 \%$ ( $\mathrm{X}^{2}=14,00 ; 1$ g.l.). Verificamos que a associação é positiva entre o grupo que teve meningite e o grupo dos que morreram (casos 2, 3, 24, 35, 43, 52, 65 e 86), ou apresentaram maus resultados (casos $30,27,63,69,71,73,83,84$ e 85); isto equivale a dizer que o resultado bom se associou à ausência de meningite.

A infecção foi responsável pelos 9 casos de óbito de tôda a série. O exame do LCR confirmou meningite em todos êles, exceto nos casos 43 e 53 , nos quais deduzimos a ocorrencia de meningite por informações prestadas por carta pelos familiares. 
Obito e mau resultado

Bom resultado

\begin{tabular}{lrc}
\hline Com meningite & 12 & 12 \\
Sem meningite & 6 & 54 \\
& - & 66
\end{tabular}

Tabela 3 - Associação entre resultado e ocorrência de complicação infecciosa em casos com seguimento superior a dois meses.

Duas criancas apresentaram hematoma subdural. Uma delas (caso 73), submetida à derivaçāo ventriculoatrial direita, foi reoperada 21 meses após, devido ao mau funcionamento do sistema, tendo sido realizada DVA esquerda. Decorridos 5 nos desta revisão a criança comecou a apresentar cefaléia, vômitos e sonoléncia. A radiografia do crânio mostrou rotura dos dois cateteres, próxima à válcula do lado esquerdo. Foi indicada revisāo, que consistiu em DVP esquerda, com o uso da válvula de Hakim de pressão média. Cinco mese após, a eriança voltou a apresentar cefaléia, vômitos e sonoléncia. Teve também crise convulsiva focal direita. $O$ eletrencefalograma mostrou sofrimento cerebral à esquerda e a angiografia coleção subdural esquerda. Com o esvaziamento do hematoma a crianca apresentou melhora progressiva.

O outro paciente (caso 66) foi submetido à derivaçāo ventriculoperitoneal direita com válvula de Hakím de pressão baixa. A cirurgia foi realizada de urgência, devido á gravidade do quadro clínico. Dois meses após, foi indicada revisão que consistiu na troca do cateter ventricular. Uma semana depois o paciente apresentou hipertensão intracraniana, com quadro neurológico grave de comprometimento do tronco cerebral. O estudo angiográfico mostrou coleção subdural direita que foi drenada. O paciente permaneceu por longo tempo em coma, com crises de rigidez descerebrada. Lentamente houve melhora progressiva, com recuperaça da consciéncia.

Uma criança (caso 48) foi reinternada, dois meses após a instalação do sistema de drenagem, com perfuração intestinal e exteriorização do cateter peritoneal pelo ânus. Foi indicada nova cirurgia que consistiu na retirada do sistema; realizada a desconexão, o cateter peritoneal foi tracionado e retirado pelo ânus. Não apareceu qualquer sintomatologia abdominal. Um mês após, nôvo sistema de drenagem foi instalado à esquerda. O periodo de seguimento, após a complicação, foi de 28 meses. Não surgiu qualquer intercorréncia, apresentando-se a criança com hidrocefalia compensada, fontanelas fechadas e sistema de drenagem funcionante.

Em trés pacientes (casos 31, 37 e 45) ocorreram oclusōes do catêter peritoneal por 6 vêzes. No caso 31 , o sistema funcionou bem de início. Após 36 meses, a criança começou a apresentar períodos de hipertensão intracranlana. A sequêencia do estudo radiológico demonstrou progressiva disjunção de suturas. Foi feita a troca de todo o sistema de drenagem, verificando-se oclusão parcial do cateter peritoneal, por fibrina. Trés meses depois o estudo do funcionamento do sistema de drenagem mediante radioisótopos, demonstrou a permeabilidade do mesmo, com drenagem satisfatória.

Dezesseis meses após a DVP, outro paciente (caso 37) apresentou descompensaçäo por bloqueio do cateter peritoneal, revelada pelo teste mecânico de funcionamento do sistema. Foi realizada DVP esquerda, que também deixou de funcionar 5 meses após, por oclusäo do cateter peritoneal. A revisāo cirúrgica para troca do cateter mostrou que o mesmo se apresentava ocluido por fibrina. Este paciente necessitou mais duas revisões, com intervalos de dois e nove meses, para troca de cateter peritoneal ocluído. Depois desta última revisão a criança foi acompanhada por 4 meses, apresentando periodos de descompensação. 
No caso 45, a oclusāo do cateter peritoneal verificou-se 24 meses após a derivação para o peritônio. O cateter peritoneal, que foi trocado, encontrava-se ocluido por fibrina. Mais duas reoperações foram necessárias, em virtude de bloqueio do cateter ventricular. Esta criança após a troca do cateter peritoneal, foi acompanhada por um periodo de 6 meses, permanecendo com o sistema funcionando satisfatòriamente.

Após a derivaçāo ventriculoperitoneal, foram feitas 8 revisōes em 6 casos por oclusāo ou rotura do cateter ventricular. A rotura do cateter, verificada no estudo radiológico, ocorreu em uma criança (caso 74) que tinha sido submetida à derlvação ventriculoatrial. Após 81 meses de funcionamento, o sistema foi transformado em ventriculoperitoneal, em virtude de oclusāo do cateter atrial. Na revisão foi mantido o mesmo cateter ventricular. Decorridos 8 meses da drenagem para o peritônio e, portanto, 89 meses de uso do cateter ventricular, o mesmo rompeu-se próximo à válvula, tendo sido substituido. Dois pacientes (casos 19 e 45) foram reoperados duas vêzes por oclusão do cateter ventricular. Os bloqueios ocorreram, respectivamente, com intervalos de 24 e 9 meses e 24 e três meses. Nos demals (casos 29, 65 e 66) a oclusāo verificou-se uma só vez (24, 2 e 2 meses após a DVP). Em todos os casos o bloqueio foi confirmado pelo ato cirúrgico.

Acreditamos que duas outras crianças (casos 83 e 85) apresentaram bloqueio parcial do cateter ventricular pois a válvula não enchia de modo satisfatório.

Causas do óbito - Em todos os 9 casos de óbito houve processo infeccioso do sistema nervoso central.

Trés pacientes (casos 2,3 e 86) foram submetidos à necropsia. Em todos êles o processo infeccioso havia ocorrido no pós-operatório imediato da drenagem pará o peritônio. No caso 3 , após a intercorrência infecciosa foi retirado o sistema de derivação e, nos demais, foi feito apenas tratamento clínico. A necropsia evidenciou, nos casos 2 e 86, meningite, e, no caso 3 , meningite e ventriculite. Em nenhum desses casos foi encontrada peritonite.

Seis pacientes nāo foram submetidos à necropsia (casos 24, 35, 43, 52, 53 e 65). Dois (casos 43 e 53) faleceram em hospital de suas cidades de origem e, segundo informacōes, o obito ocorreu por meningite. Nos demais, o exame do LCR confirmou meningite, que foi responsável pelo óbito destas crianças.

\section{Condiçōes atuais do sistema de drenagem:}

Sistema funcionando perfeitamente (45 casos) - Trinta e uma crianças não foram reoperadas; 5 sofreram uma revisão (casos 23, 29, 31, 41 e 74), 8 sofreram duas revisões (casos $16,30,48,51,56,62,78$ e 82 ) e uma foi reoperada três vêzes (caso 45).

Sistema de drenagem funcionando mal (4 casos) - Um paciente (caso 37) foi operado 4 vêzes em virtude de oclusões repetidas do cateter peritoneal; após a última revisão foi acompanhado por 4 meses apresentando períodos de descompensação. Dois pacientes (casos 71 e 84) apresentaram periodos de descompensação 2 e 4 meses após DVP. No primeiro caso houve necessidade de trocar o sistema; 5 meses após, o paciente voltou a apresentar periodos de descompensação, durante os quais havia necessidade de bombar a válvula (seguimento de 17 meses após a revisāo). No segundo casos, foi possivel controlar a descompensação, bombando-se a válvula várias vêzes ao dia (seguimento de três meses). Para o caso 85, seis meses apsó instalação de nôvo sistema à esquerda, verificou-se o enchimento deficiente da válvula. O paciente passa por pequenos periodos de descompensação controlados com medicamentos.

Sistema de drenagem retırado por complicacāo infecciosa (4 casos) - Em dols pacientes (casos 6 e 46), o sistema foi retirado 6 e 17 meses após a DVP, não 
tendo surgido descompensação. Foram seguidos por mais 41 e 7 meses respectivamente. Nos outros dois pacientes (casos 60 e 73), após a retirada do sistema, houve descompensação transitória. Para o caso 60 , em que o sistema foi retirado no pós-operatório imediato, a severidade da descompensação exigiu nova drenagem que também foi retirada, após um mês de uso. O paciente foi acompanhado por mals 10 meses, passando por periodo transitório de descompensação. No caso 73 , que também apresentou como intercorrência a formação de hematoma subdural, praticou-se 4 reoperaçōes. Após a retirada do sistema, houve periodo transitório de descompensação (seguimento de 9 meses).

Derivaçāo subduroperitoneal (um caso) - Em um paciente (caso 66), uma semana após troca do cateter ventricular, surgiu hematoma subdural, que foi tratado por drenagem subduroperitoneal, com interposição da válvula de Hakim. Após a cirurgia foi acompanhado por 13 meses, apresentando melhora lenta e progressiva.

Operaçōes anteriores - Para verificar se a realização de uma DVA, antes da DVP, influenciou o resultado, fizemos o estudo comparativo (Tabela 4), verificando, mediante análise pelo método do $\mathrm{X}^{2}$, com correção para continuidade, não haver diferença significante entre as duas amostras $\left(\mathrm{X}^{2}=1,27 ; 1 \mathrm{g.l.}\right)$. Foram excluidos os casos com seguimento inferior a dois meses.

\begin{tabular}{lccc}
\hline & DVA anterior & Sòmente DVP \\
\hline Resultado mau & 2 & 16 \\
Resultado bom & 12 & 54 & $\frac{16}{70}$ \\
\hline
\end{tabular}

Tabela 4 - Associacão entre resultado e existência ou não de DVA anterior.

Com o objetivo de verificar se a realização de uma DVA, antes da DVP, influenciou a ocorrência de revisões cirúrgicas, fizemas estudo comparativo (Tabela 5), tendo a análise pelo método do $\mathrm{X}^{2}$, com correção para continuidade, mostrado não haver diferença significante entre as duas amostras $\left(X^{2}=1,31 ; 1\right.$ g.1.). Foram excluidos os casos com seguimento inferior a dois meses.

\begin{tabular}{llr}
\hline & \multicolumn{3}{c}{ Revisão } \\
\cline { 2 - 4 } & Com & Sem \\
\hline Com DVA anterior & 8 & 6 \\
Sem DVA anterior & 4 & 10 \\
\hline
\end{tabular}

Tabela 5 - Associação entre revisão e existência ou não de DVA anterior.

O estudo realizado demonstra que o bom ou mau resultado e a ocorrência de revisões cirúrgicas não se associam ao fato de ter sido o paciente antes submetido à DVA. 
Necessidade de revisões cirúrgicas - $\mathrm{O}$ número de revisões cirúrgicas nos pacientes hidrocefálicos costuma ser grande, quaisquer que sejam as técnicas cirúrgicas tentadas. Realizamos uma revisão na casuística de Almeida, que consta de 136 pacientes hidrocefálicos submetidos à derivação ventriculoatrial no período de dezembro de 1958 a dezembro de 1965, nos mesmos Serviços em que foram operados os pacientes de nossa casuística. Procuramos estabelecer uma comparação entre o número de revisōes cirúrgicas efetuadas em ambas amostras.

Verificamos que, entre os pacientes submetidos à derivação ventriculoperitoneal, a porcenatgem de revisões cirúrgicas, nos primeiros 6 meses, foi maior $(39,5 \%)$ do que a encontrada entre os casos submetidos à derivação ventriculoatrial $(25,83 \%)$. Considerando as reoperações feitas, 6 a 12 meses após o ato cirúrgico, observamos que no grupo submetido à DVA, o índice pouco se alterou $(23,61 \%)$, ao passo que para a DVP diminuiu consideràvelmente $(11,45 \%)$. De fato, entre as crianças submetidas a derivação ventriculoperitoneal, as reoperações foram mais comuns nas primeiras semanas (mediana de 1,3 meses). Para avaliar o problema das revisões cirúrgicas, em se considerando também os resultados, elaboramos uma "Tábua de Vida" (Tabela 6), que é um estudo referente às probabilidades de "sobrevivência" a uma revisão cirúrgica ao óbito ou a seqüela neurológica grave. Esta "Tábua de Vida" inicia estudando o total da amostra por periodos de 30 dias, até o nonagésimo dia de pós-operatório. Segue-se uma avaliação de grupos de pacientes, considerando periodos de 90 ou 180 dias e terminando com periodo de observação de 1260 a 1440 dias, a fim de não aumentarmos muito o número de classes. Quando os pacientes que constam de um determinado período de observação, sofrem revisōes cirúrgicas, morrem, apresentam seqüelas graves ou encerram seu periodo de seguimento, vão sendo eliminados da amostra.

Verificamos mediante êsse estudo que, nos primeiros três meses, 28,51\% das crianças apresentaram intercorrências traduzidas por seqüelas neurológicas graves, óbito ou revisão cirúrgica. Passado êsse periodo inicial os resultados tendem a melhorar. De fato, considerando uma evolução de 6 meses, $33,71 \%$ dos pacientes apresentaram as referidas intercorrência.

A metodologia empregada permite verificar que, após 4 anos, 42,35\% dos pacientes estão em boas condições não tendo sofrido novas intervenções cirúrgicas, o que representa um porcentual bastante satisfatório.

Complicações infecciosas - Os sistemas de derivação ventriculoperitoneal e ventriculoatrial criam um ambiente no qual as defesas do organismo agem precàriamente e os antibióticos, mesmo quando injetados no ventrículo lateral, chegam muito diluídos. Estabelecem-se, portanto, condições propicias para a proliferação de germes, muitas vêzes considerados não patogênicos quando alojados em outros locais. Todavia, parece-nos que, nos pacientes com derivação ventriculoperitoneal, o processo infeccioso é mais fàcilmente controlado, por não haver introdução de germes na corrente sangüínea. Na maioria 
dos casos, em que foi necessária a retirada do istema de drenagem, observamos que o contrôle do processo infeccioso se efetuou prontamente. Isto permitiu que, uma vez comprovada a persistência da descompensação, nova drenagem fôsse logo colocada.

\begin{tabular}{|c|c|c|c|c|c|c|c|c|c|c|}
\hline 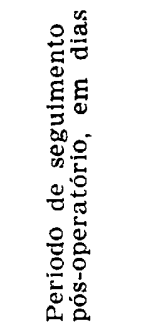 & 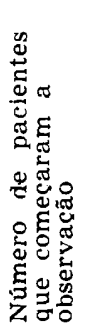 & $\underset{\stackrel{P}{*}}{\stackrel{8}{x}}$ & 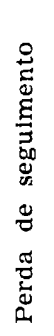 & 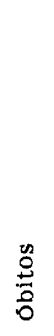 & 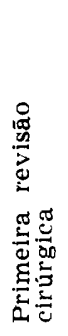 & 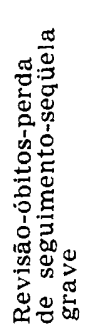 & 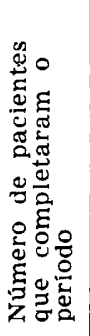 & 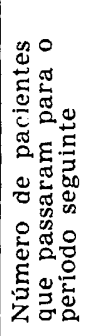 & 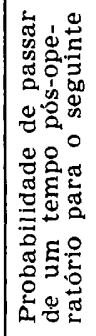 & 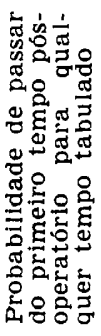 \\
\hline $0-\quad 30$ & 95 & 83 & 10 & 3 & 10 & 22 & 85 & 73 & 85,88 & 100,00 \\
\hline $30-60$ & 73 & 65 & 1 & 2 & 7 & 9 & 72 & 64 & 88,89 & 85,88 \\
\hline $60-90$ & 64 & 60 & 1 & 2 & 3 & 5 & 63 & 59 & 93,65 & 76,34 \\
\hline $90-180$ & 59 & 55 & 4 & 2 & 3 & 8 & 55 & 51 & 92,73 & 71,49 \\
\hline $180-270$ & 51 & 49 & 5 & - & 2 & 7 & 46 & 44 & 95,65 & 66,29 \\
\hline $270-360$ & 44 & 44 & 3 & - & 0 & 3 & 41 & 41 & 100,00 & 63,41 \\
\hline $360-450$ & 41 & 41 & 12 & - & 0 & 12 & 29 & 29 & 100,00 & 63,41 \\
\hline $450-540$ & 29 & 28 & 0 & - & 1 & 1 & 29 & 28 & 96,55 & 63,41 \\
\hline $540-630$ & 28 & 27 & 4 & - & 1 & 5 & 24 & 23 & 95,83 & 61,22 \\
\hline $630-720$ & 23 & 22 & 1 & - & 1 & 2 & 22 & 21 & 95,45 & 58,67 \\
\hline $720-900$ & 21 & 19 & 4 & - & 2 & 6 & 17 & 15 & 88,23 & 56,00 \\
\hline $900-1080$ & 15 & 15 & 2 & - & 0 & 2 & 13 & 13 & 100,00 & 49,41 \\
\hline $1080-1260$ & 13 & 12 & 6 & - & 1 & 7 & 7 & 6 & 85,71 & 49,41 \\
\hline $1260-1440$ & 6 & 5 & 3 & - & 1 & 4 & 3 & 2 & 100,00 & 42,35 \\
\hline
\end{tabular}

Tabela 6 - "Tábua de Vida" - Probabilidades de "sobrevivência" a uma revisão cirúrgica ao óbito e a seqüela neurológica grave.

Com o objetivo de tratar com mais eficácia o processo infeccioso, têm sido apresentadas modificações técnicas, que permitem a introdução de antibiticos diretamente no interior do sistema de drenagem ${ }^{36}$. Esta medida, ainda em estudos, visa a combater o processo infeccioso, sem retirar o sistema. Um paciente de nossa casuística (caso 56) foi operado com o uso da válvula de Hakim e de reservatório apropriado à colheita de LCR e introdução de antibióticos; no pós-operatório imediato ocorreu meningite; foi feita antibioticoterapia, por via sistêmica e diretamente no reservatório; conseguimos cura clinica e laboratorial apenas temporária, sendo necessário retirar o sistema, 4 meses aps o início do quadro infeccioso.

Procurando diminuir o risco de infecção nos pacientes subrnetidos à DVP, Weiss e Raskind ${ }^{42}$ administraram antibióticos profilàticamente, em um grupo de 15 pacientes; comparando os resultados com um grupo de 15 pacientes que 
não receberam antibióticos, concluíram que o seu uso é desnecessário e injustificável.

Em nossa casuística a análise dos resultados mostrou que os problemas infecciosos constituem a principal causa de complicações. $O$ estudo estatístico comprovou a piora dos resultados quando ocorre meningite e $87,03 \%$ das reoperaçōes foram determinadas por complicações infecciosas.

Realizando estudo comparativo entre a ocorrência de meningite nos casos operados no Hospital das Clínicas da FMUSP e em Hospital Particular (Tabela 7), aplicamos o método do $\mathrm{X}^{2}$ que mostrou diferença não significante $\left(\mathrm{X}^{2}=0,17 ; 1 \mathrm{~g} .1.\right)$, o que mostra que a incidência de meningite foi a mesma nos casos operados em ambos hospitais. Foram excluídos das amostras os casos com seguimento inferior a dois meses.

\begin{tabular}{|c|c|c|c|}
\hline \multirow{2}{*}{ Procedēncia dos pacientes } & \multicolumn{2}{|c|}{ Meningite } & \multirow{2}{*}{ Total } \\
\hline & Com & Sem & \\
\hline Hospital particular & 10 & 28 & 38 \\
\hline \multirow[t]{3}{*}{ Hospital das Clinicas da FMUSP } & 14 & 32 & 46 \\
\hline & - & - & 一 \\
\hline & 24 & 60 & 84 \\
\hline
\end{tabular}

Tabela 7 - Associação entre a ocorrência de meningite e o local onde foram operados os pacientes.

Em 4 pacientes (casos 5, 12, 29 e 48), que apresentaram quadro clínico de meningite pós-operatória, conseguimos a cura da infecção sem que houvesse necessidade de retirar o sistema de drenagem. A sipercitose encontrada no LCR destas 4 crianças foi moderada, e em nenhuma delas foi possivel isolar o agente etiológico. Por outro lado, em alguns doentes com LCR e quadro clínico semelhantes ao destas crianças tivemos que retirar a derivação para cura completa.

Callaghan, Cohen e Stwart ${ }^{7}$, analisando as intercorrências infecciosas nos pacientes submetidos à DVA, salientam a necessidade da retirada do sistema para cura completa da infecção. Os dados por nós referidos sugerem que para os pacientes submetidos à DVP, esta conduta poderá sofrer restrições.

Analisamos pelo método do $\mathrm{X}^{2}$, com correção para continuidade, a associação entre meningite e a existência de meningocele (Tabela 8) que mostrou diferença não significante $\left(\mathrm{X}^{2}=0,66 ; 1 \mathrm{~g} .1.\right)$. Acreditamos que êste resultado seja devido ao número relativamente pequeno de casos. De fato, a necessidade de outro ato cirúrgico e a existência de deficits esfincterianos lògicamente aumentam o risco de infecção. Foram excluídos da amostra os casos com menos de dois meses de seguimento pós-operatório. 


\begin{tabular}{lcccc}
\hline & \multicolumn{3}{c}{ Meningite } & Total \\
\cline { 2 - 3 } Meningocele & Com & Sem & \\
\hline Com & 2 & 11 & 13 \\
Sem & 22 & 49 & 71 \\
& - & -60 & -8 \\
\hline
\end{tabular}

Tabela 8 - Associação entre meningite e existência ou não de meningocele.

Salientamos que em nenhum dos pacientes com intercorrência infecciosa ocorreu peritonite severa. Acreditamos que, com maior desenvolvimento das técnicas de assepsia, a freqüência de complicações infecciosas deva diminuir, melhorando os resultados.

Oclusão do cateter peritoneal - Durante o periodo desencorajador da prática da derivação do LCR para o peritônio, sem o uso de válvula, foram relatados casos esporádicos em que o sistema de drenagem permanecia funcionando por longo tempo $4,14,20,21,32,37$. Ames ${ }^{4}$ teve, por duas ocasiōes, oportunidade de observar a cavidade peritoneal 24 e 28 meses aps DVP, referindo que não havia acúmulo de $L C R$ e que o cateter permanecia livre, não formando aderências com as alças intestinais. Fischer e Shillito ${ }^{17}$, por ocasião de laparotomias para tratamento de cistos abdominais, também verificaram que o cateter não aderia às alças. Weiss e Raskind ${ }^{41}$ constataram, com estudo radiográfico, que o cateter se movimenta livremente dentro da cavidade peritoneal.

Foram registrados alguns casos em que houve problemas de reabsorção do LCR. Ames ${ }^{4}$ faz referência a um paciente que, dois anos após a DVP, apresentou ascite volumosa, tendo a punção da cavidade abdominal mostrado que o líquido acumulado era o próprio LCR. Fischer e Shillito ${ }^{17}$ apresentaram três doentes com volumosos cistos abdominais $(6,15$ e 20 meses após a instalação da drenagem), admitindo que esta complicação se relacione a fenômeno inflamatório, na decorrência de processos infecciosos ou intervenções repetidas na cavidade peritoneal. Intercorrência semelhante foi relatada por Tischer ${ }^{39}$ e Harsh $^{20}$.

Com o uso de válvula unidirecional, no sistema de drenagem, a oclusão da extremidade peritoneal tornou-se rara $4,8,11,34,39,40,41,42$.

Murtagh e Lehman ${ }^{30}$, usando o sistema ventriculoatrial de Pudenz, com a extremidade distal delgada, realizaram DVP em 7 crianças hidrocefálicas. Os resultados não foram bons, devido à oclusão do cateter peritoneal no pósoperatório imediato, na maioria dos casos. Três crianças da nossa casuística (casos 31, 37 e 45) apresentaram bloqueio do cateter peritoneal, que tornou necessária revisão cirúrgica. No caso 37 ocorreu a oclusão 4 vêzes, tendo sido praticadas 4 revisões cirúrgicas. Acreditamos que o sistema de drena- 
gem de dois de nossos pacientes (casos 71 e 84) esteja parcialmente ocluído na extremidade distal. Estas crianças apresentam periodos de descompensação, durante os quais é necessário bombar a válvula, para aumentar o fluxo de drenagem.

Muitas vêzes o teste de bombar a válvula não permite avaliar, com precisão, o funcionamento da drenagem. Têm sido propostos métodos mais objetivos para elucidar dúvidas. Quando se usa o sistema de Ames, podem ser injetados 5 a 10 cc de ar em uma das cápsulas; o estudo radiográfico permitirá a verificaçāo do funcionamento do sistema ${ }^{41}$. O emprêgo de radioisótopos, aplicável a qualquer tipo de drenagem, fornece dados quanto à permeabilidade e também quanto à quantidade de LCR drenado em determinado tempo ${ }^{13}, 16,27,{ }^{28}$. No caso 31 , três meses após revisão cirúrgica, foi realizado cintilograma cerebral e abdominal após introdução de substância radioativa no ventrculo lateral direito, tendo sido verificado ser excelente o funcionamento da drenagem.

Devido à baixa incidência de oclusão do cateter peritoneal, na derivação ventriculoperitoneal com válvula, julgamos que o método tem grande valor no tratamento cirúrgico da hidrocefalia.

Outras complicações - Hematoma subdural foi observado em dois pacientes (casos 66 e 73). Intercorrência semelhante tem sido referida após DVP $^{3,42}$ derivação ventriculoatrial ${ }^{2,25}$, ou outros ripos de tratamento cirúrgico da hidrocefalia $5,12,22$. O grande volume dos ventriculos e a reduzida espessura do pálio cerebral criam condições que facilitam o aparecimento do hematoma subdural, de modo especial quando a hipertensão intracraniana está controlada. Nas duas crianças que tiveram hematoma subdural tinham sido usadas válvulas de Hakim. E possível que a maior capacidade de drenagem do LCR, pelo sistema de Hakim, tenha favorecido a formação dos hematomas, por colapso cerebral.

Perfuração intestinal foi observada em um paciente (caso 48). Após retirada do sistema a evolução foi satisfatória, não tendo surgido manifestações clinicas de peritonite ou meningite; esta criança havia apresentado, no. pós-operatório imediato da primeira DVP, quadro de meningite que foi curada sem haver necessidade de retirar o sistema.

Chakravorty $^{8}$ relata um caso em que houve perfuração intestinal, seguida de peritonite fatal. Wilson e Bertan ${ }^{43}$ relataram dois casos nos quais, 3 e 10 meses aps o atos cirúrgico, o cateter foi eliminado pelo ânus. Uma das crianças faleceu com peritonite e a outra evoluiu satisfatòriamente. Em nenhum dos casos houve processo infeccioso do sistema nervoso central.

Dependência do sistema de drenagem - Analisando 63 hidrocefálicos submetidos à DVA, Foltz ${ }^{18}$ concluiu que uma vez feita a derivação, ela seria sempre necessária, admitindo que algumas crianças teriam probabilidades de tornar-se independentes da derivação, se fosse seguida conduta conservadora, porém, isto ocorreria às expensas de sacrifícios da capacidade intelectual. 
Entre nós, Almeida ${ }^{2}$ é de opinião de que não se justifica revisão cirúrgica sistemática, nos doentes em que a válvula deixa de funcionar; para os casos com intercorrências infecciosas, em que há necessidade de retirar o sistema, preconiza conduta expectante, por alguns dias; se, durante o periodo necessário à cura da infecção, o caso evoluir bem, indicando que a hidrocefalia compensou-se, nôvo ato cirúrgico é dispensável. Essa mesma conduta teve continuidade nos pacientes de nossa casuistica. Alguns casos apresentaram boa evolução após retirada do sistema de drenagem, sem que maior sofrimento do encéfalo fôsse observado.

Estudo compurativo entre DVA e DVP - A derivação ventriculoperitoneal apresenta diversas vantagens sôbre a derivação ventriculoatrial. A drenagem para o peritônio é simples de ser instalada, dispensando dissecções, por vêzes difíceis, de veias da região cervical e o contrôle intra-operatório mediante radiografias ou eletrocardiograma ${ }^{26}$. Weiss e Raskind ${ }^{41}$ realizam a DVP em 15 minutos e Raimond e Matsumoto ${ }^{34}$ a praticam em crianças com anestesia local.

Nos pacientes submetidos à DVA, as intercorrências infecciosas podem acarretar manifestaçōes clínicas graves (septicemia ${ }^{6}$, bacteremia ", endocardite ${ }^{33}$, glomerulonefrite, abscessos múltiplos pulmonares e/ou renais). Além disso, outras complicaçōes severas podem ocorrer nos pacientes com derivação ventriculoatrial: trombose da veia cava e átrio direito ${ }^{10}$, microembolismo ${ }^{31}$, fibrose pulmonar e cor pulmonale crônico ${ }^{53}$, deslocamento do cateter para as cavidades cardíacas $^{1}$ e perfuração do miocárdio ${ }^{15}$.

Como os nossos casos (submetidos à DVP) e os de Almeida (submetidos à DVA) foram tratados nos mesmos Serviços, em condiçōes semelhantes, julgamos ser interessante comparar os resultados obtidos. Para isto revimos as condições dos pacientes das duas séries, considerando o seguimento pósoperatório de 6 meses e de um ano. Na tabela 9 estão resumidas as porcentagens de óbito nas duas séries. Verificamos que nos 6 primeiros meses as porcentagens de óbito são semelhantes. No fim do período de observação, o resultado foi melhor para os pacientes submetidos à DVP.

\begin{tabular}{lllll}
\hline & \multicolumn{3}{c}{ Evolução pós-operatória em anos } \\
\cline { 2 - 4 } & 0 a & 0,5 & 0,5 a & 1 \\
Tipo de intervenção & DVA & DVP & DVA & DVP \\
Número de casos & 118 & 77 & 93 & 58 \\
Porcentagens de óbito & 15,25 & 11,68 & 2,15 & 0,0 \\
\hline
\end{tabular}

Tabela 9 - Verificaçio das porcentagens de óbito nos pacientes da série de Almeida (DVA) e nos pacientes de nossa casuistica (DVP). 
Na tabela 10 comparamos os resultados quanto ao número de óbito e funcionamento da derivação, após um ano de seguimento.

\begin{tabular}{|c|c|c|c|c|c|}
\hline \multirow[b]{2}{*}{ Cirurgia } & \multicolumn{4}{|c|}{$R$ e s u l t a d o s } & \\
\hline & Obito & $\begin{array}{c}\text { Derivaçāo } \\
\text { funcionando } \\
\text { bem }\end{array}$ & $\begin{array}{c}\text { Derivacão } \\
\text { funcionando } \\
\text { mal }\end{array}$ & $\begin{array}{c}\text { Sem } \\
\text { válvula }\end{array}$ & \\
\hline DVA & 20 & 75 & 12 & 4 & 111 \\
\hline DVP & 9 & 51 & 1 & 6 & 67 \\
\hline
\end{tabular}

A análise estatística pelo método do $\mathrm{X}^{2}$ mostrou haver diferença significante entre as duas séries $\left(\mathrm{X}^{2}=8,07 ; 3 \mathrm{~g} .1\right.$.). Isto confirma que a derivação ventriculoperitoneal com válvula oferece melhores resultados.

\section{RESUMO E CONCLUSOES}

Uma série de 95 crianças hidrocefálicas foram submetidas à derivação ventriculoperitoneal (DVP) com válvula no periodo de dezembro de 1965 a novembro de 1969 . Os resultados obtidos são analisados e comparados com os obtidos mediante derivação ventriculoatrial (DVA).

Das crianças operadas, 54 estão vivas e com a hidrocefalia compensada, 9 faleceram, não sendo possivel estabelecer as condições atuais das 32 restantes. Com a derivação para o peritônio foram evitadas as severas complicações vasculares e cardiopulmonares observadas com a derivação para a cvidade cardíaca. O número de revisões cirúrgicas é menor nos pacientes submetidos à DVP com válvula. Além disso, as infecções no sistema de drenagem ventriculoperitoneal provocam quadros menos graves e de mais fácil solução, que os observados na derivação ventriculoatrial. A análise das condições pré-operatórias, das complicações e dos resultados finais permitiram algumas conclusões: 1) o uso de válvula unidirecional, no sistema de derivação ventriculoperitoneal, dificulta a oclusão da extremidađe distal do sistema de drenagem; 2) pode-se esperar bons resultados, sem necessidade de revisão cirúrgica, em cêrca de $42,35 \%$ das crianças hidrocefálicas submetidas à DVP com válvula; 3 ) as derivações ventriculoperitoneais com válvula, quando comparadas às derivações ventriculoatriais, considerando um grupo de crianças hidrocefálicas operadas nos mesmos Serviços, em condições semelhantes, com mesmo tempo de seguimento - foram as que proporcionaram melhores resultados; 4) os casos estudados permitem constatar, portanto, que a DVP com válvula, constitui atualmente a terapêutica cirúrgica mais apropriada da hidrocefalia infantil. 


\section{SUMMARY AND CONCLUSIONS}

Evaluation of the ventriculo-peritoneal shunt with valve in the
treatment of hydrocephalus

From December-1965 to November-1969, 95 hydrocephalic infants have been operated upon using ventriculoperitoneal shunt with valve ( 88 cases with a Spitz-Holter valve, 6 cases with a Hakim valve and one case with a Pudenz-Heyer valve).

Up to the present time (December, 1970) a total of 54 children are alive with a compensated hydrocephalus and 9 patients died, being impossible to follow-up the 32 remaining cases. The use of the ventriculoperitoneal shunt has eliminated all cardiovascular-pulmonary complications and reduced the number for surgical revisions. Besides, infections involving the draining system are less severe and more easily controlled than those occurring in the ventriculoatrial shunts. After analysis of the surgical techniques as well as complications and results the following conclusions are stated: 1) the use of a valve in the ventriculoperitoneal shunt difficults the oclusion of the peritoneal end of the draining system; 2) good results can be expected without reoperations in about $42,35 \%$ of hydrocephalus cases treated by ventriculoperitoneal shunt with valve; 3 ) ventriculoperitoneal shunts with valve showed better results when compared to ventriculoatrial shunts. This statement is made comparing two groups of hydrocephalic infants submitted to surgery at the same Service and in the same conditions, with the same follow-up period; 4) the cases presented permit to state that at present time the ventriculoperitoneal shunt with valve is the most suitable surgical procedure for hydrocephalus.

1. ALMEIDA, G. M. - Corpo estranho intracardiaco: complicação da ventriculoauriculostomia. Arq. Neuro-Psiquiat. (Sāo Paulo) 23:201, 1965.

2. ALMEIDA, G. M. - Derivação ventrículo-atrial no tratamento da hidrocefalia em crianças. Arq. Neuro-Psiquiat. (Sāo Paulo) 27:1, 1969.

3. ALMEIDA, G. M. \& PEREIRA, W. C. - Derivação ventriculoperitoneal com válvula no tratamento da hidrocefalia do lactente. Arq. Neuro-Psiquiat. (São Paulo) 27:308, 1969.

4. AMES, R. H. - Ventriculoperitoneal shunts in the management of hydrocephalus. J. Neurosurg. 27:525, 1967.

5. ANDERSON, F. M. - Subdural hematoma: a complication of operation for hydrocephalus. Pediatrics 10:11, 1952.

6. ANDERSON, F. M. - Ventriculo-auriculostomy in treatment of hydrocephalus. J. Neurosurg. 16:551, 1959.

7. CAllaghaN, R. P.; COHEN, S. J. \& STEWART, G. T. - Septicemia due to colonization of Spitz-Holter valves by staphylococci. Five cases trested with Methicilin. British med. J. 1:860, 1961.

8. CHAKRAVORTY, A. - Modified ventriculopertitoneal shunt in the treatment of hydrocephalus. J. Indian med. Ass. 44:293, 1965.

9. COHEN, S. J. \& CALLAGHAN, R. P. - A syndrome due to the bacterial colonization of Spitz-Holter valves. A review of five cases. British med. J. $2: 677,1961$. 
10. CROME, L. \& ERDOHAZI, M. - Main pathological findings in hydrocephalic children treated by ventriculo-atrial shunt. Arch. Dis. Childh. 41:179, 1966.

11. DAKTERS, J. G.; YASHON, D.; CROFT, T. J. \& WHITE, R. J. - Cerebrospinal fluid diversion. Arch. Surg. 96:56, 1968.

12. DAVIDOFF, L. M. \& FEIRING, E. H. - Subdural hematoma occuring in surgically treated hydrocephalic children: with a note on a method of handling persistent accumulations. J. Neurosurg. 10:557, 1953.

13. DI CHIRO, G. \& GROVE, A. S. - Evaluation of surgical and spontaneous cerebrospinal fluid shunts by isotope scanning. J. Neurosurg. 24:743, 1966.

14. DICKSON, H. B. \& ECKSTEIN, M. J. - Shunt surgery in hydrocephalus after blockage of both internal jugular veins. Develop Med. Child. Neurol. 16:110, 1968.

15. DZENITIS, A. J.; MEALEY Jr. \& WADDEL, J. R. - Myocardial perforation by ventriculo-atrial shunt tubin. J. Am. med. Ass. 194:1251, 1965.

16. FACURE, J. J.; FACURE, N.; CAMARA, A. J. \& OTERO, N. R. --- Verificaçào do funcionamento de derivaçōes ventriculoperitoneais com válvula mediante emprêgo de radioisótopos: contribuição técnica pessoal. Arq. Neuro-Psiquiat. (São Paulo) 29:234, 1971.

17. FISCHER, E. G. \& SHILLITO Jr., J. - Large abdominal cysts: a complication of peritoneal shunts. Report of three cases. J. Neurosurg. 31:441, 1969.

18. FOLTZ, E. L. - The first seven years of a hydrocephalus project. In Shulman, K. - Workshop in Hydrocephalus. University of Pcanylvania Press, Philadelphia, 1965 . pp. 79-114.

19. HAKIM, S.; ZULUAGA, A. \& CABRERA, O. - Derivación Ventriculo-atrial para el Tratamiento de la Hidrocefalia por Medio de la Válvula Hakim. Cooperativa, Bogotá, 1964.

20. HARSH, G. R. - Peritoneal shunt for hydrocephalus, utilizing the fallopian tube for entrance to the peritoneal cavity. J. Neurosurg. 11:294, 1954.

21. JACKSON, I. J. \& SNODRAUSS, S. R. - Peritoneal shunts in treatment of hydrocephalus and increased intracranial pressure; four year survey of 62 patients. J. Neurosurg. 12:216, 1955.

22. JONES, R. F. C. - Long-term results in various treatments of hydrocephalus. J. Neurosurg. 26:313, 1967.

23. LAURENCE, K. M. \& COATES, S. - Spontaneously arrested hidrocephalus. Results of the re-examination of 82 survivors from a serie of 182 unoperated cases. Develop. Med. Child. Neurol.; Suppl. 13:4, 1967.

24. LEFEVRE, A. B.; ZACLIS, J. \& VALENTE, M. I. - Hidrocefalia ou hidranencefalia. Valor da transiluminação do crânio no diagnóstico diferencial. Estudo anátomo-c'linico de dois casos. Arq. Neuro-Psiquiat. (São Paulo) 13:325, 1965.

25. LEPOIRE, J. \& LAPRAS, C. - Traitment de l'hydrocéphalie non tumorale du nourrison par la dérivation ventriculo-atriale. Neuro-chirurgie (Paris) 18:209, 1967.

26. MARK, V. H. \& SWEET, W. H. - Ventriculo-atriostomy: a technical note: The accurate placement of the distal end of the shunt into the right atrium without X-ray control. Neurochirurgia 3:115, 1960.

27. McCUllough, D. C. \& LUESSENHOP, A. J. - Evaluation of photoscaning of the diffusion of intrathecal risa in infantile and childhood hydrocephalus. J. Neurosurg. 30:673, 1968.

28. Migliore, A.; PAOletTI, P. \& VIllani, R. - Radioisotopic method for evaluating the patency of the Spitz-Holter valve. J. Neurosurg. 19;605, 1962.

29. MIGLiore, A.; PAOLETTI, P. \& VILLANI, R. - The rate of exchange of $\mathrm{Na}_{24}$ and other ions between plasma and cerebrospinal fluid in normal subjects and in hydrocephalic infants. Develop. Med. Child. Neurol. 1:310, 1965.

30. MURTAGH, F. \& LEHMAN, R. - Peritoneal shunts in the management of hydrocephalus. J. Am. med. Ass. 202:1010, 1967. 
31. NULSEN, F. E. \& BECKER, D. P. - The control of progressive hydrocephalus in infancy by valve-regulated venous shunt. In Shulman, K. - Workshop in Hydrocephalus. University of Pennsylvania Press, Philadelphia, 1965. pp. 115137.

32. PICAZA, J. A. - The posterior-peritoneal shunt technique for the treatment of internal hydrocephalus in infants. J. Neurosurg. 13:298, 1956.

33. PLAUT, M.; SOIFER, I. \& VALSAMIS, M. - Bacterial endocarditis complicating ventriculoatrial shunt. N. Y. med. J. 62:1856, 1962.

34. RAIMONDI, A. J. \& MATSUMOTO, S. - A simplifield technique for performing the ventriculo-peritoneal shunt. J. Neurosurg. 26:357, 1967.

35. RAO, P. S.; MOLTHAN, M. E. \& LIPOW, H. W. - Cor pulmonale as a complication of ventriculoatrial shunts. J. Neurosurg. 33:221, 1970.

36. RICKHAM, P. P. \& PENN, I. A. - The place of the ventriculostomy reservoir in the treatment of myelomaningoceles and hydrocephalus. Develop. Med. Child. Neurol. $7: 296,1965$.

37. SCOTT, M.; WYCIS, H. T.; MURTACH, F. \& REYES, V. - Observations on ventricular and lumbar subarachnoid peritoneal shunts in hydrocephalus in infancts. J. Neurosurg. 12:165, 1955.

38. SPITZ, E. B. - Neurosurgery in the prevention of exogenous mental retardation. Pediat. Clins N. Am, 6:1215, 1959.

39. TISCHER, W. - Vergleichend Ergebnisse peritonialer und ventrikulolarer Drainagen beim frühkindlichen Hydrozephalus. Neurochirurgia 12:127, 1969.

40. TURNER, E. - Demonstration of a low-impedance valve. Develop. Med. Child. Neurol. $4: 303,1962$.

41. WEISS, S. R. \& RASKIND, R. - Twenty-two cases of hydrocephalus treated with a silastic ventriculoperitoneal shunt. Int. Surg. 51:13, 1969

42. WEISS, E. R. \& RASKIND, R. - Further experience with the ventriculoperitoneal shunt: prophylatic antibioties. Int. Surg. 53:300, 1970.

43. WILSON, C. B. \& BERTAN, V. - Perfuration of the bowel complicating perineal shunt for hydrocephalus. Am. Surg. 32:601, 1966.

Clínica Neurológica - Faculdade de Ciências Médicas - Universidade Estadual de Campinas - Caixa Postal 1170 - 13100 Campinas SP - Brasil. 